\title{
Three-dimensional electron density along the WSA and MSNA latitudes probed by FORMOSAT-3/COSMIC
}

\author{
F. Y. Chang ${ }^{1}$, J. Y. Liu ${ }^{1,2^{*}}$, L. C. Chang ${ }^{1}$, C. H. Lin ${ }^{3}$ and C. H. Chen ${ }^{3}$
}

\begin{abstract}
In this paper, we employ electron density profiles derived by the GPS radio occultation experiment aboard the FORMOSAT-3/COSMIC (F3/C) satellites to examine the electron density on geographic latitudes of $40^{\circ}$ to $80^{\circ}$ in the Southern hemisphere and $30^{\circ}$ to $60^{\circ}$ in the Northern hemisphere at various global fixed local times from February 2009 to January 2010. The results reveal that an eastward shift of a single-peak plasma density feature occurs along the Weddell Sea Anomaly (WSA) latitudes, while a double-peak plasma density feature appears along the northern Mid-latitude Summer Nighttime Anomaly (MSNA) latitudes. A cross-comparison between three-dimensional F3/C electron density and HWM93 simulation confirms that the magnetic meridional effect and vertical effect caused by neutral winds exhibit the eastward shifts. Furthermore, we find that the eastward shift of the peaks when viewed as a function of local time suggests that they could be interpreted as being comprised of different tidal components with distinct zonal phase velocities in local time.
\end{abstract}

Keywords: FORMOSAT-3/COSMIC; WSA; MSNA; Neutral wind effect

\section{Background}

The Weddell Sea Anomaly (WSA) was first observed by ground-based ionosondes over Antarctica during the International Geophysical Year in 1957 (Bellchambers and Piggott 1958). The WSA is characterized by the electron density in the $F$ region around the Weddell Sea area being larger during nighttime (1800-0200 LT) than during daytime (0800-1800 LT) in the Southern Hemisphere summer (Bellchambers and Piggott 1958; Penndorf 1965; Dudeney and Piggot 1978) and in the equinoctial seasons (Jee et al. 2009). Recently, remote sensing and in situ observations (Burns et al. 2008; Lin et al. 2009, 2010; Jee et al. 2009; He et al. 2009; Liu et al. 2010) indicate that the WSA extends over a much larger region than originally thought: spanning between South America and Antarctica and extending to the central Pacific region. These studies suggest that the major physical mechanisms for the WSA formation are the equatorward neutral wind, $\mathbf{E} \times \mathbf{B}$ drift,

\footnotetext{
* Correspondence: jyliu@jupiter.ss.ncu.edu.tw

${ }^{1}$ Institute of Space Science, National Central University, Taoyuan 320, Taiwan ${ }^{2}$ Center for Space and Remote Sensing Research, National Central University, Taoyuan 320, Taiwan

Full list of author information is available at the end of the article
}

photoionization, and downward diffusion from the plasmasphere. Chen et al. (2011) conducted simulations using the SAMI2 model (Huba et al. 2000) and reported that the equatorward neutral wind is a major cause of the WSA, while the downward flux from the plasmasphere provides an additional plasma source to enhance or maintain the density of the nighttime feature.

The satellite observations have not only helped to renew the WSA's large-scale morphology but have also resulted in clearly studying the WSA-like feature in the Northern Hemisphere during local summer (cf. Lin et al. 2010). Lin et al. $(2009,2010)$ reported that the WSA-like feature in the Northern Hemisphere spanning the East Asia-East Pacific and Central Europe regions showed two- or threepeak regions. The feature was confirmed by Thampi et al. (2009) using tomographic observation near East Asia (135 E longitude) and in situ measurement from the CHAMP satellites by Liu et al. (2010) and Burns et al. (2011). The phenomena in the Northern Hemisphere together with the WSA are generally referred to as the Mid-latitude Summer Nighttime Anomaly (MSNA) (Thampi et al. 2009) or summer evening anomaly (Burns et al. 2011). Recently, de Larquier et al. (2011) observed the MSNA feature using 
Super Dual Auroral Radar Network (SuperDARN) radars over North America and Japan as well as the Millstone Hill ISR (incoherent scatter radar) during the April-September period, and suggested that the phenomena may also occur near the equinox season. Liu et al. (2010) indicate that the two or three distinct regions of the MSNA results from a combination of the neutral wind effect in the geomagnetic frame, photoionization, and the thermal contraction of the ionosphere at sunset. The simulations of Thampi et al. (2011) and Chen et al. (2011) reach similar conclusions that the neutral wind is the dominant effect, and the zonal electric field can also contribute to modify the MSNA. Meanwhile, scientists (Liu and Yamamoto 2011; Zakharenkova et al. 2012; Cherniak et al. 2014) examine storm effects providing further evidence to the pivot role of effective neutral wind in the formation of MSNA.

Jee et al. (2009) examined TOPEX total electron content (TEC) measurements and reported the TEC enhancements of the WSA at night initially form over the whole Pacific sector in the evening but gradually tapers to the far eastern Pacific region near the midnight and moves slightly eastward over the nighttime. On the other hand, Chen et al. (2013) conducted model simulations and report possible eastward drifts around the WSA regions during 2200-0600 LT in December solstice. They also identified the zonally symmetric D0 nonmigrating diurnal tide to be large in field-line-integrated vertical neutral winds in this region, noting that the D0 tidal component appears as an eastward propagating wave- 1 feature when viewed in a local time frame. This mechanism was confirmed using in situ CHAMP and GRACE observations by Chao and Luhr (2014), who reported that the diurnal eastward propagation of WSA-like features is caused by the D0 tide in the Southern Hemisphere and DE1 in the Northern Hemisphere. Recently, the tidal decomposition has been applied to TEC and/or electron density derived from inversion of TEC using radio occultation technique of FORMOSAT3/COSMIC (F3/C), to quantify the components dominating local time and spatial variation in the WSA region (Chang et al. 2015). Liu et al. (2014) and Chang et al. (2012) showed that the eastward drift of the three-dimensional F3/C electron density with HWM93 field-aligned winds agree with the eastward movements of the WSA.

In this study, we expand on those previous studies and examine three-dimensional electron density in the ionosphere and the neutral wind effect to explore the structure of the single-peak and double-peak plasma density respectively appearing along the WSA and northern MSNA latitudes in both hemispheres whole year. The F3/C satellite constellation is used to globally investigate the eastward shift at various global fixed local times and seasons from February 2009 to January 2010. To confirm the importance of neutral the wind, we also compute the effects of the eastward/meridional wind by Horizontal Wind
Model 1993, HWM93, (Hedin et al. 1996) and declination/ inclination angle from the International Geomagnetic Reference Field (IGRF-11).

\section{Methods}

The F3/C data are subdivided into 4 months, M-month (March Equinox \pm 45 days), J-month (June Solstice \pm 45 days), S-month (September Equinox \pm 45 days), and D-month (December Solstice \pm 45 days), to study seasonal effects during the geomagnetic quiet years 2009 and 2010. The data in each month are binned with resolutions of $1^{\circ}$ in latitude, $1^{\circ}$ in longitude, and $20 \mathrm{~km}$ in altitude every $2 \mathrm{~h}$. Since there are 5000-7000 data points of bad profiles, $15-16 \%$ being out of the median value of each bin for each month (Yue et al. 2010), the median value is robust. Figure 1 shows the ionospheric electron density at 300-km altitude in the Southern Hemisphere of the 4 months. The electron density significantly enhances over the WSA region, occurring over a large area between $30-80^{\circ} \mathrm{S}$ geographic and $0-150^{\circ} \mathrm{W}$ geographic, which slightly shifts eastward at 2100-0700 LT during the D-month. In fact, this enhancement feature also clearly appears at the same local times during the $\mathrm{M}$ - and S-month.

As extensively discussed by Titheridge (1995), the neutral wind plays a predominant role in the variation of $F$ region parameters at middle latitude by lifting up or lowering the $F$ region ionization. Its actual effect depends on the configuration of the magnetic field. Its actual effect depends on the configuration of the magnetic field. Let $V_{x}$ and $V_{y}$ be the geographically meridional (equatorward positive) and zonal (eastward positive) wind components derived by HWM93, where $D$ and $I$ are the magnetic declination and inclination angles obtained from International Geomagnetic Reference Field (IGRF-11), respectively. Hence, the fieldaligned wind in magnetic meridional effect $(U)$ and vertical effect $(W)$ can be computed and expressed as,

$$
\begin{aligned}
& U=\left(V_{x} \cos D \pm V_{y} \sin D\right) \cos ^{2} I \\
& W=\left(V_{x} \cos D \pm V_{y} \sin D\right) \cos I \sin I
\end{aligned}
$$

Here, the plus and minus signs apply to the Southern and Northern Hemisphere. From the above, it can be seen that even the assumed neutral winds being uniform in longitude in geographic coordinates can produce significant longitudinal variation in the plasma density under geomagnetic coordinates due to the variation of $D$ and $I$. We further compare the electron density with $U$ (white arrows) and the longitudinal maximum $W\left(W_{\mathrm{M}}\right.$, white circle-dots in each of plots) at $300-\mathrm{km}$ altitude at $75^{\circ} \mathrm{S}$ during the 4 months. The enhanced electron density obviously shows an eastward phase shift together with the longitudinal maximum $U\left(U_{\mathrm{M}}\right.$, the longest white arrow in each of plots) and $W_{\mathrm{M}}$ in the M-, S-, and D-month. 


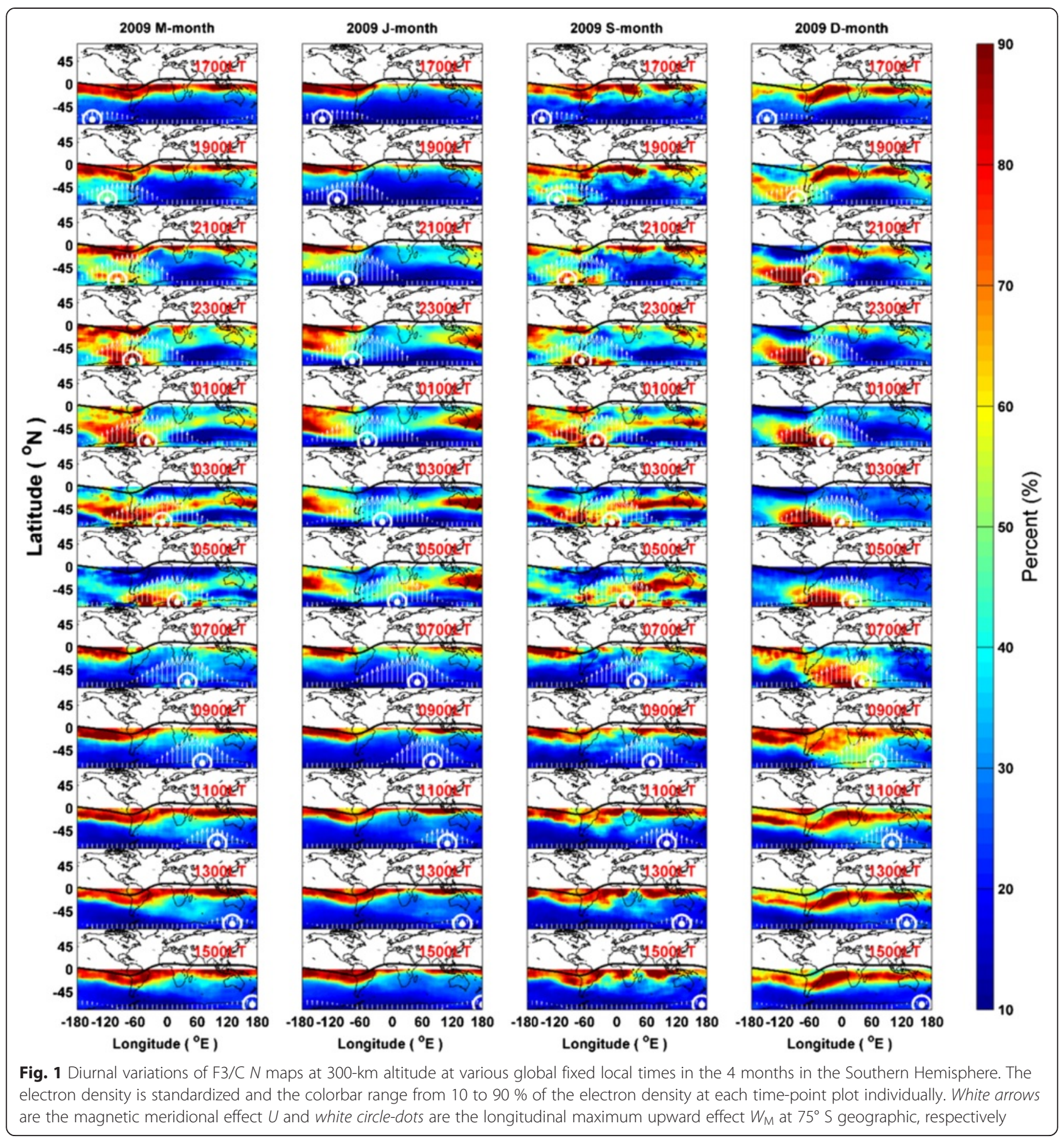

The four upper panels of Fig. 2 show the F3/C electron density at $100-700-\mathrm{km}$ altitude of $40-80^{\circ} \mathrm{S}$ geographic as well as the meridional and vertical effects at $300-\mathrm{km}$ altitude of $75^{\circ} \mathrm{S}$ geographic during the 4 months. When the two effects reach their $U_{\mathrm{M}}$ (black circle-dots in each of plots) and $W_{\mathrm{M}}$ (the longest black arrows in each of plots), the electron density at about $300-\mathrm{km}$ altitude also approaches its longitudinal maximum value $\left(N_{\mathrm{M}}\right)$ and the ionospheric $F_{2}$-peak ascends from $200 \mathrm{~km}$ to the highest altitude of $300-350 \mathrm{~km}$ in the 4 months. The exception is during the J-month (i.e., winter in the Southern Hemisphere), when $N_{\mathrm{M}}$ and the $F_{2}$-peak are relatively low in both electron density and altitude. During this time, the two effects reach their longitudinal minimum $U\left(U_{\mathrm{m}}\right.$, black circle-crosses in each plots) and longitudinal minimum $W$ ( $W_{\mathrm{m}}$, the largest downward arrow or the smallest upward arrow), and the ionospheric $F_{2}$ region descends to $200-\mathrm{km}$ altitude. Therefore, the electron density at about $300-\mathrm{km}$ 


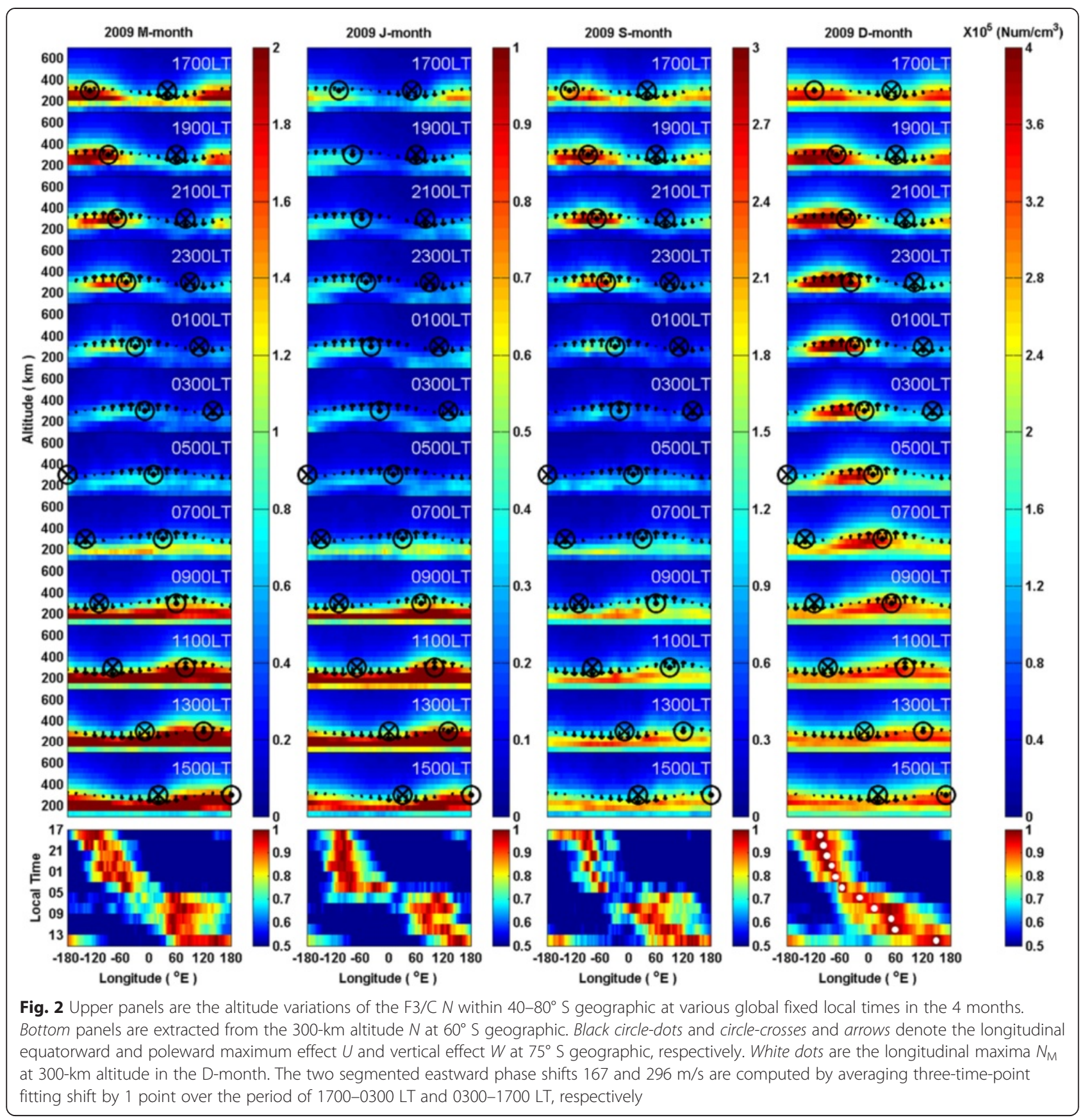

altitude reaches its longitudinal minimum values $\left(N_{\mathrm{m}}\right)$. It can be seen that again, $U_{\mathrm{M}}$ and $W_{\mathrm{M}}$ and $N_{\mathrm{M}}$ as well as $U_{\mathrm{m}}$ and $W_{\mathrm{m}}$ and $N_{\mathrm{m}}$ all simultaneously shift eastward together. We further extract the electron density at $300-\mathrm{km}$ altitude within $40-80^{\circ} \mathrm{S}$ geographic in the 4 months as shown in the bottom four slices of Fig. 2. Results show that the eastward phase shift yields two speeds of $167 \mathrm{~m} / \mathrm{s}$ during 1700-0300 LT and $296 \mathrm{~m} / \mathrm{s}$ during 0300-1700 LT, and the co-located $U_{\mathrm{M}}$ and $W_{\mathrm{M}}$ lead $N_{\mathrm{M}}$ by about $2-5 \mathrm{~h}$. Similar results of eastward phase shift can be observed from $U_{\mathrm{m}}$ and $W_{\mathrm{m}}$ and the associated $N_{\mathrm{m}}$, accordingly.
Figure 3 illustrates the ionospheric electron density at 300-km altitude, $U$, and $W_{\mathrm{M}}$ in the Northern Hemisphere at various global fixed local times during the M-, J-, S-, and D-month. Two groups of both $N_{\mathrm{M}}$ between $30^{\circ}$ and $60^{\circ} \mathrm{N}$ geographic and $U_{\mathrm{M}}$ and $W_{\mathrm{M}}$ at $55^{\circ} \mathrm{N}$ geographic, simultaneously exhibit eastward phase shift in the J-month (i.e., summer in the Northern Hemisphere). The upper four panels of Fig. 4 display the electron density at 100-700-km altitude within $30^{\circ}$ to $60^{\circ} \mathrm{N}$ geographic versus the two effects at $55^{\circ} \mathrm{N}$ geographic at various global fixed local times in the 4 months. Two enhanced regions of electron 


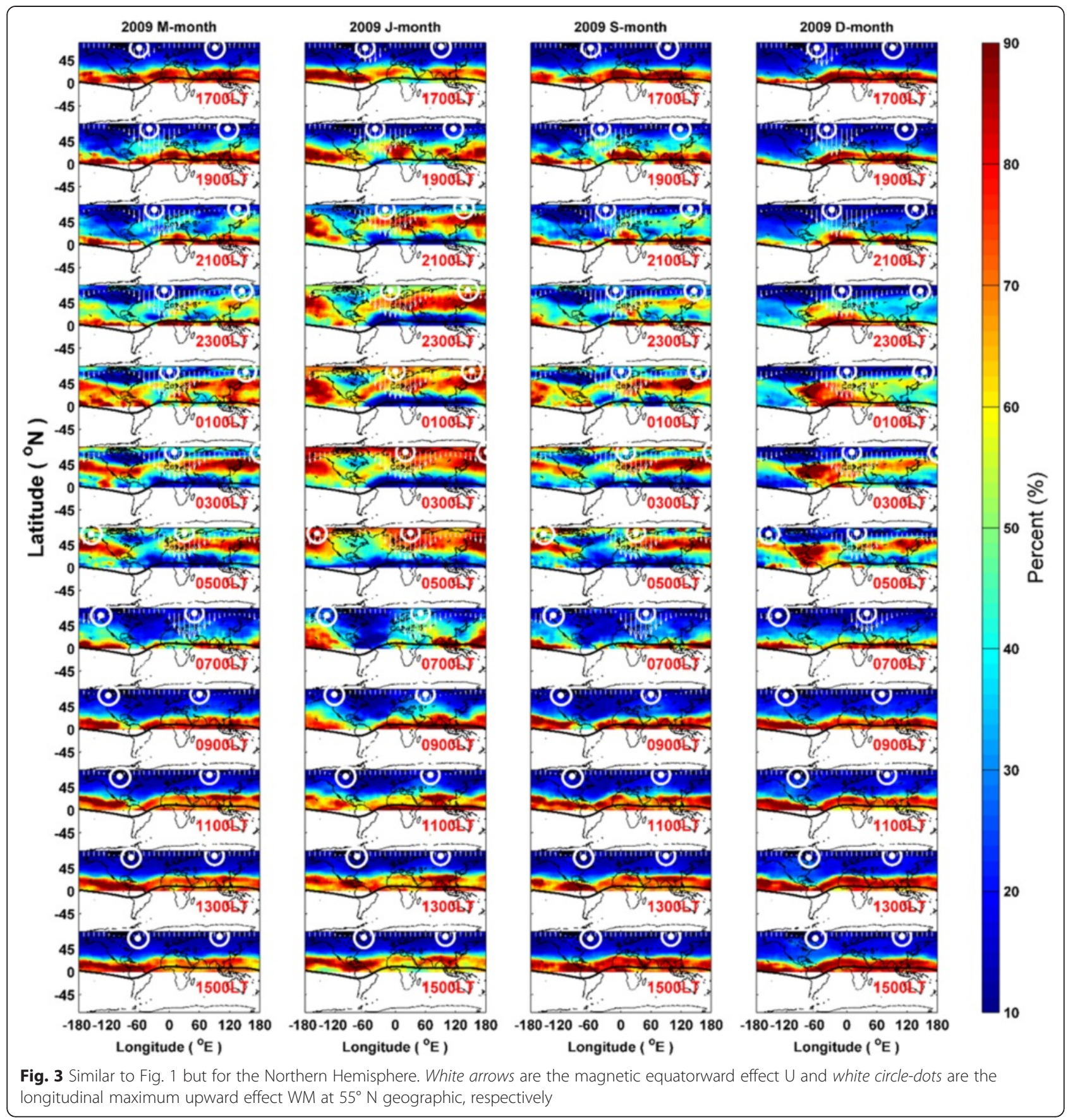

density at $30-60^{\circ} \mathrm{N}$ appear at each global fixed local time. It is clear that the electron density reaches the two maxima at about $250-\mathrm{km}$ altitude, $N_{\mathrm{M}}$, during the J-month. Thus, we further isolate and examine the electron density at 250$\mathrm{km}$ altitude. Similarly, in comparing the other 3 months, $N_{\mathrm{M}}$ and F2-peak are relatively rarefied and low in the Dmonth (i.e., winter in the Northern Hemisphere). The two groups, $N_{\mathrm{M}}$ in $135^{\circ} \mathrm{E}-115^{\circ} \mathrm{W}$ geographic and $50^{\circ} \mathrm{W}-100^{\circ}$ E geographic, reveal eastward phase shift with 91 and $121 \mathrm{~m} / \mathrm{s}$, respectively (see the bottom slices of Fig. 4).

\section{Results and discussion}

Figures 1 and 2 reveal enhanced electron densities that are in agreement with the WSA feature in the D-month reported previously (cf. Liu et al. 2010). On the other hand, two enhanced regions of electron density, especially at 1700-2100 LT, appear at northern middle latitudes (Figs. 3 and 4), and agree with the northern MSNA reported by Lin et al. (2009). In previous studies, the WSA and northern MSNA have been well known as anomalous enhancements of the nighttime electron density. However, 


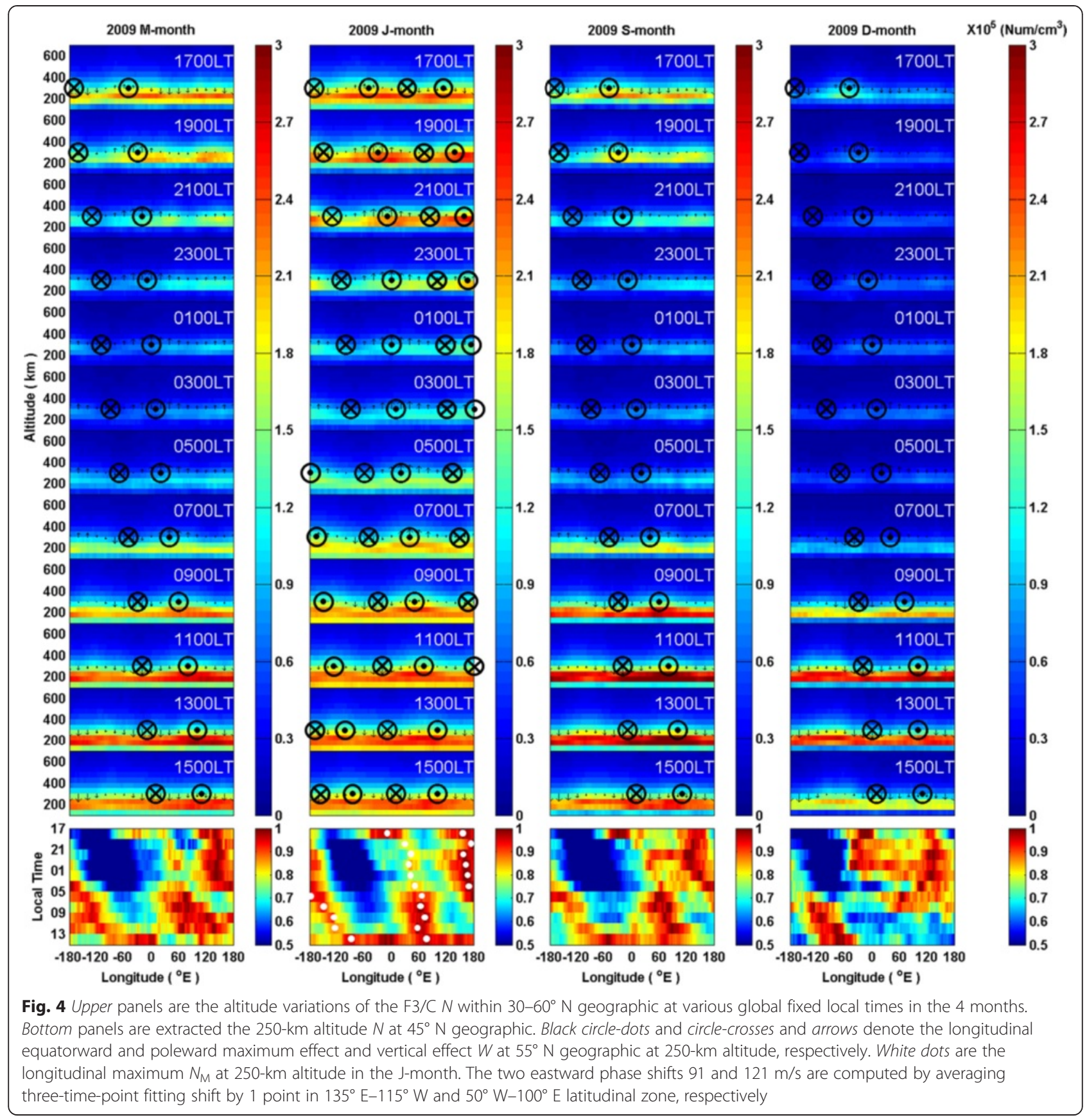

the $\mathrm{F} 3 / \mathrm{C}$ observations in this study show that the anomalous enhancements along the WSA and northern MSNA latitudes in both hemispheres are not specific nighttime features but exist over the whole day (see the bottom slices of Figs. 2 and 4). The existing observations and simulations show that the physical mechanisms for the WSA and northern MSNA formation could be attributed to the equatorward neutral wind, $\mathrm{E} \times \mathrm{B}$ drift, photoionization, and downward diffusion from the plasmasphere (Burns et al. 2008; Lin et al. 2009, 2010; Liu et al. 2010; de Larquier et al. 2011; Chen et al. 2011). Chen et al. (2011) further reported that the equatorward wind is dominant. The research in this paper reveals that when the magnetic equatorward and upward effect reach their maxima, the ionospheric height and electron density also approaches the maximum in the 4 months. These features agree with the previous results that due to the equatorward neutral wind, plasma moves to higher altitudes. This causes the collision and loss processes to become much slower. Consequently, the ionosphere yields maxima in both electron density and layer height. The maximum of the electron density lags those of the two plasma flows by about $2-5 \mathrm{~h}$. Kakinami et al. 2011 showed 
that the longitudinal structures of $\mathrm{Ne}$ could be caused not only by meridional wind but also by zonal wind driving dynamo effects, especially those of the modulated electric field by nonmigrating tides which may modify the longitudinal structures of $\mathrm{Ne}$ in the ionosphere. Therefore, the delay time of about $2-5 \mathrm{~h}$ between $\mathrm{Ne}$ and the equatorward and upward plasma flows suggest that the longitudinal structure of $\mathrm{Ne}$ in ionosphere is produced not only by meridional wind effects but also by the modulated electric field by nonmigrating tides in the dynamo region. Nevertheless, the simultaneous eastward shifts in the two plasma flows as well as ionospheric electron density and height confirm that the equatoward and upward plasma flows owing to neutral wind effects are the most essential.

Jee et al. (2009) observed that the electron density enhancement moves slightly eastward in the WSA region over the nighttime, while Liu et al. (2014) and Chang et al. (2012) showed the F3/C electron density with a global eastward phase shift in various local times. Chao and Luhr (2014) presented a description of the southern and northern MSNA in terms of solar tidal signatures focusing on $40^{\circ}-60^{\circ}$ geomagnetic latitude ranges, which is the region where the reversed diurnal variations of the electron density are strongest from the solar minimum years 2008 and 2009. They attributed the eastward propagation of these features as being the result of the dominant diurnal standing (D0 tide) and the eastward wavenumber 1 (DE1 tide), both of which appear to have eastward phase velocities when viewed in local time. Additionally, Chang et al. (2015) suggested that the WSA not only can be reconstructed as the result of superposition between the D0 tide and DE1 tide but also westward wavenumber 2 (DW2 tide) and stationary planetary wave 1 (SPW1 tide) components in TECs, producing the characteristic midnight WSA peak. The D0, DE1, DW2, and SPW1 components were found to be an interannually recurring feature of the southern midto high-latitude ionosphere during the summer, manifesting as enhancements in electron density around $300-\mathrm{km}$ altitude of the summer mid to high magnetic latitudes. The phases of the aforementioned nonmigrating diurnal signatures in electron density in this region are near evanescent, suggesting in situ generation, rather than upward propagation from below. However, the SPW1 signature showed some signs of upward propagation. The sources of these components could be generation via in situ photoionization or plasma transport along magnetic field lines, connecting the tidal interpretation of the WSA to previously examined generation mechanisms.

Results in this paper fully agree that such eastward propagation occurs in the diurnal variations of single-peak and double-peak features appearing in the Southern and Northern Hemisphere. When expressed in local time, tidal components have zonal phase velocities of the general form $c=\left[\left(R_{E}+h\right) \Omega \cos \theta\right]\left(\frac{n}{s+n}\right)$, where $R_{E}$ is the radius of the Earth, $h$ is the altitude, $\theta$ is latitude, $\Omega=\frac{2 \pi}{24} \mathrm{~h}^{-1}, n$ is the tidal harmonic ( $1=$ diurnal, $2=$ semidiurnal,... etc.), and $s$ is the zonal wave number in the UT frame (positive eastward) (Forbes and Wu 2006). However, the changing speeds of the peaks when viewed as a function of local time suggest that they could be interpreted as being comprised of different tidal components with distinct phase velocities in local time. Our study shows the single-peak in the Southern Hemisphere with speeds of $167 \mathrm{~m} / \mathrm{s}$ during 1700-0300 and $296 \mathrm{~m} / \mathrm{s}$ during 0300-1700 LT. These speeds are similar to the values for the zonal phase velocities of 122 and $245 \mathrm{~m} / \mathrm{s}$ (123 and $246 \mathrm{~m} / \mathrm{s}$ ) obtained for the DE1 and D0 tides at a latitude of $60^{\circ} \mathrm{S}$ and $350-\mathrm{km}$ $(400-\mathrm{km})$ altitude, with deviations likely corresponding to differences in latitude and altitude. On the other hand, no obvious relation to the zonal phase velocities of DE1 and D0 (170 and $341 \mathrm{~m} / \mathrm{s}$, respectively) at a latitude of $45^{\circ} \mathrm{N}$ at 250- and/or 400-km altitude are shown for the doublepeak speeds of 91 and $121 \mathrm{~m} / \mathrm{s}$ in the Northern Hemisphere, suggesting that the tidal composition in that hemisphere may be more complex (Liu et al. 2010; Chen et al. 2012; Chao and Luhr 2014). Chen et al. (2013) observed that the vertical phase structure of the D0 tide in fieldline-integrated HWM93 neutral vertical winds suggested that it was generated in situ in the thermosphere, as opposed to being the result of vertical propagation from below. Combined with the recent observations of Chao and Luhr (2014), our work provides further evidence connecting the D0 feature in the neutral winds to the eastward shift of the southern MSNA.

\section{Conclusions}

F3/C electron density observations reveal that a diurnal varying single-peak with eastward shift along the WSA latitudes and double-peak with eastward shift along the northern MSNA latitudes appear over all $24 \mathrm{~h}$ during the 4 months observed (see the bottom slices of Figs. 2 and 4). This paper explicitly connects the tidal signatures responsible for the WSA and its eastward propagation to transport by the neutral winds. Although the maximum of the electron density lags those of the meridional and vertical effects, the simultaneous eastward shifts in the two effects as well as ionospheric electron density and height confirm that the equatorward and upward effect owing to neutral wind contributions are the most essential.

\section{Competing interests}

The authors declare that they have no competing interests.

\section{Authors' contributions}

$J Y$ and FY initiated this study. JY, FY, and LC designed the experiment, developed the methodology, performed the analysis, and drafted the manuscript. $\mathrm{CH}$ Lin and $\mathrm{CH}$ Chen collected and processed the data. All authors read and approved the final manuscript. 


\section{Acknowledgements}

This research work is partially supported by the Ministry of Science and Technology (MOST) 103-2628-M-008-001 to National Central University. The data for this paper are available at Taiwan Analysis Center for COSMIC (TACC) and COSMIC Data Analysis and Archival Center (CDAAC). Dataset name: ionPrf.

The authors wish to thank the reviewers for their useful comments and suggestions which significantly improve the presentation of this paper.

\section{Author details}

${ }^{1}$ Institute of Space Science, National Central University, Taoyuan 320, Taiwan. ${ }^{2}$ Center for Space and Remote Sensing Research, National Central University, Taoyuan 320, Taiwan. ${ }^{3}$ Department of Earth Science, National Cheng Kung University, Tainan 701, Taiwan.

Received: 8 December 2014 Accepted: 7 September 2015

\section{Published online: 21 September 2015}

\section{References}

Bellchambers WH, Piggott WR (1958) Ionospheric measurements made at Halley Bay. Nature 188:1596-1597

Burns AG, Zeng Z, Wang W, Lei J, Solomon SC, Richmond AD, Killeen TL, Kuo YH (2008) Behavior of the F2 peak ionosphere over the South Pacific at dusk during quiet summer conditions from COSMIC data. J Geophys Res 113:A12305. doi:10.1029/2008JA013308

Burns AG, Solomon SC, Wang W, Richmond AD, Jee G, Lin CH, Rocken C, Kuo YH (2011) The summer evening anomaly and conjugate effects. J Geophys Res 116:A01311. doi:10.1029/2010JA015648

Chang FY, Liu JY, Lin CH, Chen CH (2012) Neutral wind effect on mid latitude summer nighttime anomaly. Abstract \#SA31B-2146. American Geophysical Union, Fall Meeting, San Francisco, 3-7 December 2012

Chang LC, Liu H, Miyoshi Y, Chen CH, Chang FY, Lin CH, Liu JY, Sun YY (2015) Structure and origins of the Weddell Sea Anomaly from tidal and planetary wave signatures in FORMOSAT-3/COSMIC observations and GAIA GCM simulations. J Geophys Res 120(2):1325-1340. doi:10.1002/2014JA020752

Chao X, Luhr H (2014) The Mid-latitude Summer Night Anomaly as observed by CHAMP and GRACE: Interpreted as tidal features. J. Geophys. Res., doi:10.1002/2014JA019959.

Chen CH, Huba JD, Saito A, Lin CH, Liu JY (2011) Theoretical study of the ionospheric Weddell Sea Anomaly using SAMI2. J Geophys Res 116:A04305. doi:10.1029/2010JA015573

Chen CH, Saito A, Lin CH, Liu JY (2012) Long-term variations of the nighttime electron density enhancement during the ionospheric midlatitude summer. J Geophys Res 117:A07313. doi:10.1029/2011JA017138

Chen CH, Lin CH, Chang LC, Huba JD, Lin JT, Saito A, Liu JY (2013) Thermospheric tidal effects on the ionospheric midlatitude summer nighttime anomaly using SAMI3 and TIEGCM. J Geophys Res Space Physics 118:3836-3845. doi:10.1002/jgra.50340

Cherniak I, Zakharenkova I, Krankowski A (2014) Approaches for modeling ionosphere irregularities based on the TEC rate index. Earth, Planets and Space 66:165. doi:10.1186/s40623-014-0165-z

de Larquier S, Ruohoniemi JM, Baker JBH, Ravindran Varrier N, Lester M (2011) First observations of the midlatitude evening anomaly using Super Dual Auroral Radar Network (SuperDARN) radars. J Geophys Res 116:A10321. doi:10.1029/2011JA016787

Dudeney JR, Piggot WR (1978) Antarctic ionospheric research. In: Lanzerotti LJ, Park CG (eds) Upper atmosphere research in Antarctica. Ant. Res. Ser. Washington, D. C., pp 200-235

Forbes JM, Wu D (2006) Solar tides as revealed by measurements of mesosphere temperature by the MLS experiment on UARS. J Atmos Sci 63:1776-1797

He M, Liu L, Wan W, Ning B, Zhao B, Wen J, Yue X, Le H (2009) A study of the Weddell Sea anomaly observed by FORMOSAT-3/COSMIC. J Geophys Res 114:A12309. doi:10.1029/2009JA014175

Hedin AE, Fleming EL, Manson AH, Schmidlin FJ, Avery SK, Clark RR, Franke SJ, Fraser GJ, Tsuda T, Vial F, Vincent RA (1996) Empirical wind model for the upper, middle and lower atmosphere. J Atmos Terr Phys 58:1421-1447. doi:10.1016/0021-9169(95)00122-0

Huba JD, Joyce G, Fedder JA (2000) Sami2 is another model of the ionosphere (SAMI2), a new low-latitude ionosphere model. J Geophys Res 105:23,035-23,053. doi:10.1029/2000JA000035
Jee G, Burns AG, Kim YH, Wang W (2009) Seasonal and solar activity variations of the Weddell Sea Anomaly observed in the TOPEX total electron content measurements. J Geophys Res 114:A04307. doi:10.1029/2008JA013801

Kakinami Y, Lin CH, Liu JY, Kamogawa M, Watanabe S, Parrot M (2011) Daytime longitudinal structures of electron density and temperature in the topside ionosphere observed by the Hinotori and DEMETER satellites. J Geophys Res 116:A05316. doi:10.1029/2010JA015632

Lin CH, Liu JY, Cheng CZ, Chen CH, Liu CH, Wang W, Burns AG, Lei J (2009) Three dimensional ionospheric electron density structure of the Weddell Sea Anomaly. J Geophys Res 114:A02312. doi:10.1029/2008JA013455

Lin CH, Liu CH, Liu JY, Chen CH, Burns AG, Wang W (2010) Mid-latitude summer nighttime anomaly of the ionospheric electron density observed by FORMOSAT-3/COSMIC. J Geophys Res 115:A03308. doi:10.1029/2009JA014084

Liu H, Yamamoto M (2011) Weakening of the mid-latitude summer nighttime anomaly during geomagnetic storms. Earth Planets Space 63(4):371-375. doi:10.5047/eps.2010.11.012

Liu H, Thampi SV, Yamamoto M (2010) Phase reversal of the diurnal cycle in the midlatitude ionosphere. J Geophys Res 115:A01305. doi:10.1029/2009JA014689

Liu JY, Chang FY, Oyama Kl, Kakinami Y, Yeh HC, Yeh TL, Jiang SB, Parrot M (2014) Topside ionospheric electron temperature and density along the Weddell Sea latitude. J. Geophys. Res. doi:10.1002/2014JA020227.

Penndorf R (1965) The average ionospheric conditions over the Antarctic. In: Waynick AH (ed) Geomagnetism and aeronomy, Ant. Res. Ser., vol 4. AGU, Washington, D. C., pp 1-45

Thampi SV, Lin C, Liu H, Yamamoto M (2009) First tomographic observations of the Midlatitudes Summer Night Anomaly over Japan. J Geophys Res 114:A10318. doi:10.1029/2009JA014439

Thampi SV, Balan N, Lin C, Liu H, Yamamoto M (2011) Mid-latitude summer nighttime anomaly (MSNA)-observations and models simulations. Ann Geophys 29:157-165. doi:10.5194/angeo-29-157-2011

Titheridge JE (1995) Winds in the ionosphere-a review. J Atmos Terr Phys 57:1681-1714

Yue X, Schreiner WS, Lei J, Sokolovskiy SV, Rocken C, Hunt DC, Kuo YH (2010) Error analysis of Abel retrieved electron density profiles from radiooccultation measurements. Ann Geophys 28:217-222

Zakharenkova IE, Krankowski A, Shagimuratov II, Cherniak VY, Krypiak-Gregorczyk A, Wielgosz P, Lagovsky AF (2012) Observation of the ionospheric storm of October 11, 2008 using FORMOSAT-3/COSMIC data. Earth Planets Space 64(6):505-512. doi:10.5047/eps.2011.06.046

\section{Submit your manuscript to a SpringerOpen ${ }^{\circ}$ journal and benefit from:}

- Convenient online submission

- Rigorous peer review

- Immediate publication on acceptance

- Open access: articles freely available online

- High visibility within the field

- Retaining the copyright to your article

Submit your next manuscript at $>$ springeropen.com 